Article

\title{
Highly Efficient Photo-Degradation of Gaseous Organic Pollutants Catalyzed by Diatomite-Supported Titanium Dioxide
}

\author{
Xuefei Liu ${ }^{1}$, Yugan He ${ }^{1}$, Beibei Yang ${ }^{1}$, Qi Yan ${ }^{2}$ and Junjiao Yang ${ }^{1,2, *}$ \\ 1 College of Chemistry, Beijing University of Chemical Technology, Beijing 100029, China; \\ liuxf0116@163.com (X.L.); buct201093037@icloud.com (Y.H.); yangbeibei8896@163.com (B.Y.) \\ 2 Analysis and Test Center of Beijing University of Chemical Technology, Beijing University of Chemical \\ Technology, Beijing 100029, China; yanqi0604@mail.buct.edu.cn \\ * Correspondence: yangjj@mail.buct.edu.cn
}

Received: 15 February 2020; Accepted: 27 March 2020; Published: 1 April 2020

\begin{abstract}
Volatile organic compounds (VOCs) are the most harmful contaminants that have been identified, most of which are gaseous organic pollutants. In this study, $\mathrm{TiO}_{2} @$ diatomite catalysts with various loading amounts of $\mathrm{TiO}_{2}$ were fabricated using a facile solvothermal method with anhydrous ethanol as a solvent for the removal of VOCs. X-ray diffraction analysis revealed that $\mathrm{TiO}_{2}$ has an anatase phase and the introduction of diatomite has no negative effect. The catalysts were characterized using scanning electron microscopy and transmittance electron microscopy techniques. The results indicate that after introducing diatomite, $\mathrm{TiO}_{2}$ nanoparticles are mostly square-like and intact, and are uniformly immobilized in the diatomite. Finally, their photocatalytic performance was investigated using liquid ultraviolet spectrometry and gas chromatography-mass spectrometry. Among the catalysts tested, $0.35 \mathrm{TiO}_{2} @$ diatomite (with a mass ratio of $\mathrm{TiO}_{2}$ to diatomite of 0.35 ) exhibited higher photocatalytic activity than the other samples, i.e., pure $\mathrm{TiO}_{2}$ and diatomite, and could effectively remove acetone and benzene, demonstrating its potential market application and practical significance.
\end{abstract}

Keywords: gaseous organic pollutants; titanium dioxide; diatomite; photocatalysis; volatile organic compounds

\section{Introduction}

Volatile organic compounds (VOCs) are dominant components of indoor air pollutants. Mainly originating from decorative materials, such as carpets, paints, wallpapers, or PVC, they are also emitted or generated during human activities such as cooking or smoking tobacco [1-4]. Their harm to human health can thus not be ignored. The main problems resulting from VOCs have been reported by numerous researchers, such as Dai et al., who reported the characteristics and inhalation health risks of VOCs in newly renovated homes in Shanghai, China, and concluded that the concentrations of some VOCs present a mean cancer risk above the acceptable level [5]. Data on the respiratory effects of indoor air pollution among the elderly have been scarce. Therefore, Bentayeb et al. reported the effects of indoor air pollution on the respiratory health of the elderly, and found certain links between a variety of diseases, including respiratory diseases, and indoor air pollution [6]. In addition, Ye et al. estimated the acute cardiorespiratory effects of ambient volatile organic compounds, and their findings further support a link between incomplete combustion and cardiovascular health, as well as a link between atmospheric oxidation products and respiratory health [7]. The above studies have commonly concluded that VOCs are extremely harmful to human health. In addition, according to a survey conducted by the World Health Organization (WHO), the number of premature deaths 
caused by indoor pollution globally has reached 4 million per year, and the number of deaths from indoor pollution in China is as high as 111,000, or approximately 304 per day. In addition, a 2002 report published by the WHO clearly listed indoor air pollution as one of the top causes of harm to human health [8].

Therefore, it is extremely important to study technologies regarding the removal of VOCs, and VOC removal has recently been considered by numerous researchers [9-17]. The materials used in such studies are variable, and mainly include $\mathrm{TiO}_{2}, \mathrm{ZnO}, \mathrm{SnO}_{2}, \mathrm{CdS}, \mathrm{WO}_{3}$, and numerous other metal oxides. Among them, $\mathrm{TiO}_{2}$ has been widely applied owing to its low-cost, non-toxicity, and high photo-catalytic activity. For instance, Šuligoj et al. reported the use of $\mathrm{TiO}_{2}-\mathrm{SiO}_{2}$ films from organic-free colloidal $\mathrm{TiO}_{2}$ anatase nanoparticles as a photocatalyst for the removal of VOCs from air indoors [18]. In addition, Weon et al. studied an active $\{001\}$ facet-exposed $\mathrm{TiO}_{2}$ nanotube photocatalyst filter for the removal of VOCs [19]. Haghighatmamaghani, Haghighat, and Lee studied the performance of various types of commercial $\mathrm{TiO}_{2}$ in the photocatalytic degradation of a mixture of indoor air pollutants, and adopted various alcohols, ketones, aromatics, and alkanes as the target pollutants [20].

Numerous other studies have been conducted on VOC removal using $\mathrm{TiO}_{2}$ [21-27], and have made significant contributions to the photocatalytic degradation of such compounds. However, most of these studies have reported the use of pure $\mathrm{TiO}_{2}$ for achieving the photo-catalytic degradation of gaseous organic pollutants. The aggregation of pure $\mathrm{TiO}_{2}$ often limits its practical application. In addition, pure nanomaterials have their own defects, and it is therefore difficult to apply them to interior decorative materials. To solve this problem, numerous researchers are looking for a carrier for the loading of $\mathrm{TiO}_{2}$, including porous carbon materials, Metal-OrganicFrameworks, a synthetic molecular sieve, activated carbon, and many other types of artificial materials [28-31]. Not only can such materials prevent the aggregation of $\mathrm{TiO}_{2}$, they can also improve its photodegradability.

However, the above materials must be manufactured for carrier use, and a certain cost is accrued during their synthesis. Therefore, in terms of energy efficiency, it would be better to apply natural materials, such as diatomite, which is one of the most important natural materials on Earth. With rich reserves, diatomite has abundant advantages, including non-toxicity, a stable and porous structure, strong surface adsorption, and a high heat resistance. The specific metal compounds of the material and their content are shown in Table 1 [32]. The main component is silicon dioxide, the surface of which has abundant hydroxyl and silanol groups, in which the silicon element on the surface can be bonded to $\mathrm{TiO}_{2}$ with synergistic degradation of the gaseous organic pollutants [33-35]. In addition, Niu et al. prepared a novel diatomite-supported $\mathrm{MnCeOx}$ composite (MnCeOx/diatomite) characterized based on its activation of persulfate for the degradation of organic pollutants [36]. He, Luo, and $\mathrm{Yu}$ synthesized microdisk-like g- $\mathrm{C}_{3} \mathrm{~N}_{4}$ /diatomite composites utilized for the removal of methylene blue (MB) from MB/MO or MB/RhB mixed dyes [37]. Numerous other studies in this area have also been conducted [38-41]. The present study focuses on the removal of organic pollutants, the results of which will provide an exciting reference in the area of pollutant degradation.

Table 1. Chemical analyses of diatomite [32].

\begin{tabular}{cccccccccc}
\hline Composition $\%$ & $\mathrm{SiO}_{2}$ & $\mathrm{Al}_{2} \mathrm{O}_{3}$ & $\mathrm{Fe}_{2} \mathrm{O}_{3}$ & $\mathrm{~K}_{2} \mathrm{O}$ & $\mathrm{CaO}$ & $\mathrm{MgO}$ & $\mathrm{Na}_{2} \mathrm{O}$ & $\mathrm{TiO}_{2}$ & Other \\
\hline Diatomite & 86.82 & 3.21 & 1.60 & 0.56 & 0.46 & 0.43 & 0.25 & 0.15 & 6.52 \\
\hline
\end{tabular}

Thus far, $\mathrm{TiO}_{2}$ supported by diatomite has not been utilized in the degradation of gaseous organic pollutants. Herein, we report the successful application of well-designed $\mathrm{TiO}_{2} @$ diatomite as a photo-catalytic agent for the removal of gaseous organic pollutants. In addition, diatomite was selected as a carrier, and diatomite loaded with different ratios of $\mathrm{TiO}_{2}$ was used as a catalyst for the degradation of VOCs at room temperature under UV-Vis illumination. This catalyst is inexpensive and easy to prepare, and is thus a promising application for use in the field of interior decoration. 


\section{Results and Discussion}

\subsection{XRD Analysis}

Figure 1 shows the XRD patterns of the as-prepared catalysts. Both $\mathrm{TiO}_{2}$ and $\mathrm{XTiO}_{2} @$ diatomite show the coexistence of an anatase phase with no additional peak, implying that no impurity appears in $\mathrm{TiO}_{2}$ when $\mathrm{TiO}_{2}$ is supported on diatomite. As indicated in Figure 1, the intensity of the peak at $25.27^{\circ}$ decreases with an increase in the amount of diatomite. The diffraction peaks at $25.27^{\circ}, 37.82^{\circ}$, $47.94^{\circ}, 53.79^{\circ}, 54.96^{\circ}, 62.65^{\circ}, 70.22^{\circ}$, and $75.08^{\circ}$ correspond to the crystal faces (101), (004), (200), (105), (211), (204), (220), and (215) of anatase $\mathrm{TiO}_{2}$, respectively [42-44]. The peaks at $21.8^{\circ}$ and $36.5^{\circ}$ are attributed to the $\mathrm{SiO}_{2}$ features in diatomite [44]. The reflection peak of diatomite becomes relatively low compared with that of $\mathrm{TiO}_{2}$, and the pure diatomite peak is not too weak, as shown in Figure 2 below. Therefore, the introduction of diatomite cannot affect the crystal structure of the catalyst. This result is consistent with the scanning electron microscopy (SEM) and transmittance electron microscopy (TEM) characterizations.

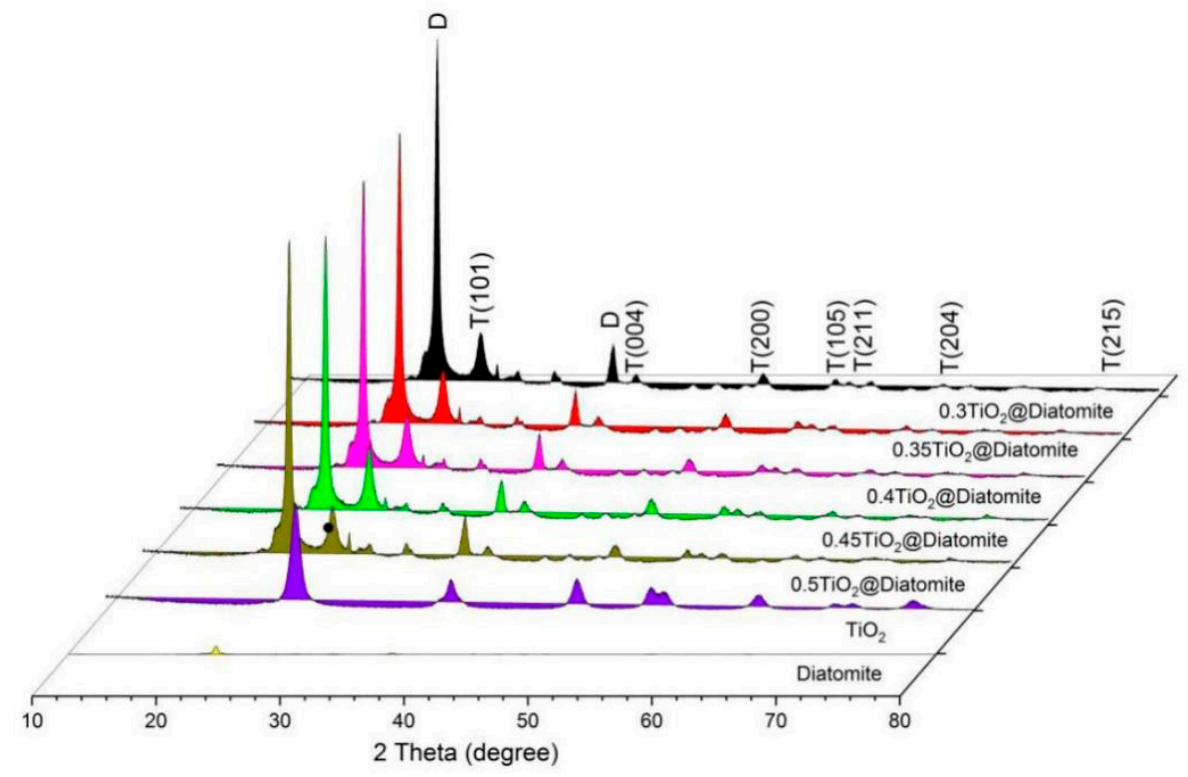

Figure 1. XRD patterns of $\mathrm{TiO}_{2}$, diatomite, and $\mathrm{XTiO}_{2} @$ diatomite.

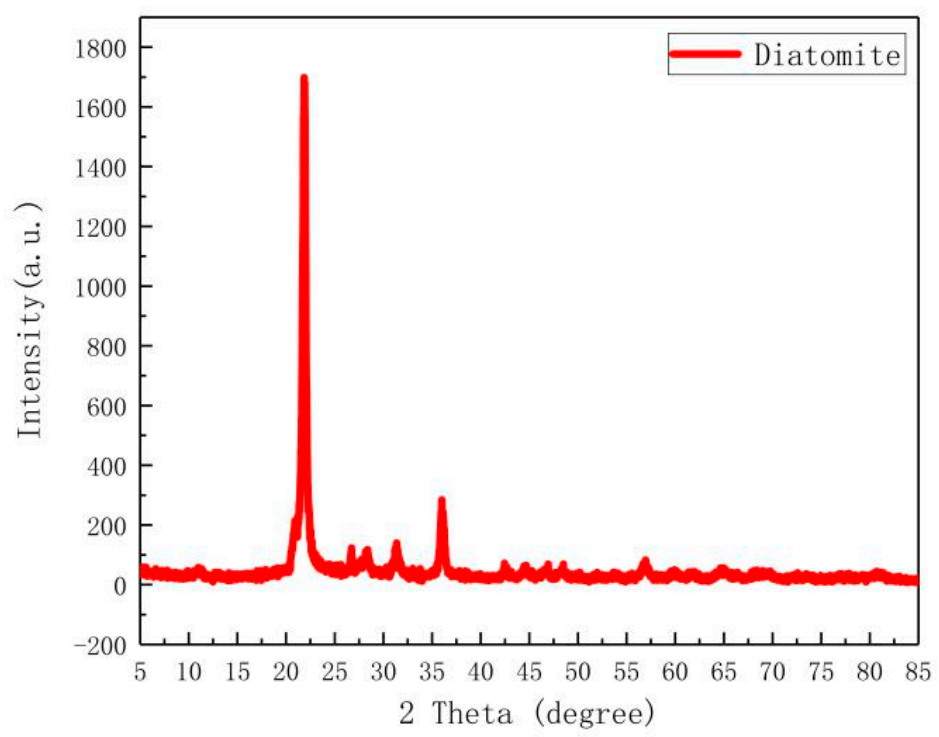

Figure 2. X-ray diffraction patterns (XRD) patterns of pure diatomite. 


\subsection{SEM and TEM Investigations}

SEM, TEM, and high-resolution transmission electron microscopy (HRTEM) images of the catalysts are shown in Figure 3. As can be seen from Figure 3(A1,A2) in the figure, diatomite without the loading of $\mathrm{TiO}_{2}$ nanoparticles looks like a sunflower with a smooth surface and numerous pores. The SEM images of pure $\mathrm{TiO}_{2}$ displayed in Figure $3(\mathrm{~B} 1, \mathrm{~B} 2)$ indicate that the $\mathrm{TiO}_{2}$ nanoparticles are square-like and approximately $10-15 \mathrm{~nm}$ in size, corresponding to the results of the TEM images (Figure 3(E1-E8)). As shown in Figure 3(C1-C6), the $\mathrm{TiO}_{2}$ nanoparticles of $0.35 \mathrm{TiO}_{2} @$ diatomite are not only uniformly loaded on the surface of the diatomite, but also adhered to the pores. This indicates that $\mathrm{TiO}_{2}$ can be firmly and evenly loaded on the surface of the diatomite. Figure 3(C1-C6) also show that the size of the $\mathrm{TiO}_{2}$ nanoparticles loaded on the surface of the diatomite is approximately 10-15 nm, which is congruent with the TEM results shown in Figure 3(E1-E8). In addition, the other load catalysts shown in Figure 3(D1-D6) were also analyzed. As indicated in D1 and D2, the load of $0.30 \mathrm{TiO}_{2} @$ diatomite is quite small, and the surface of the diatomite is thus not completely filled with $\mathrm{TiO}_{2}$, as opposed to $0.40 \mathrm{TiO}{ }_{2} @$ diatomite (Figure 3(D3,D4)), 0.45TiO2@diatomite (Figure 3(D5,D6)), and 0.50TiO $\mathrm{T}_{2} @$ diatomite (Figure 3(D7,D8)). For the latter, as the load mass increases, the degree of aggregation increases significantly, and the aggregation of $0.50 \mathrm{TiO}_{2} @$ diatomite thus becomes the most serious. There is no doubt that aggregation will cause a reduction in the photocatalytic efficiency. However, the $0.35 \mathrm{TiO}_{2} @$ diatomite load mass was moderate and evenly distributed across the diatomite surface. Therefore, the catalyst of $0.35 \mathrm{TiO}_{2} @$ diatomite may perform better than other catalysts in terms of the photocatalytic efficiency for the following two reasons: First, the proportion of $\mathrm{TiO}_{2}$ is full on the surface of the diatomite. Second, $\mathrm{TiO}_{2}$ is evenly distributed and relatively less clustered. In addition, as shown in Figure 3(E2), the lattice distance of $\mathrm{TiO}_{2}$ is approximately $0.35 \mathrm{~nm}$, corresponding to the (101) plane of anatase $\mathrm{TiO}_{2}$. As clearly shown above, the size of the $\mathrm{TiO}_{2}$ nanoparticles loaded on the diatomite is nearly the same as that of pure $\mathrm{TiO}_{2}$, indicating that the introduction of diatomite has almost no influence on the size and morphology of the $\mathrm{TiO}_{2}$. From the HRTEM images shown in Figure 3(E1-E4), it can be clearly seen that the specific shape of $\mathrm{TiO}_{2}$ is square-like. 

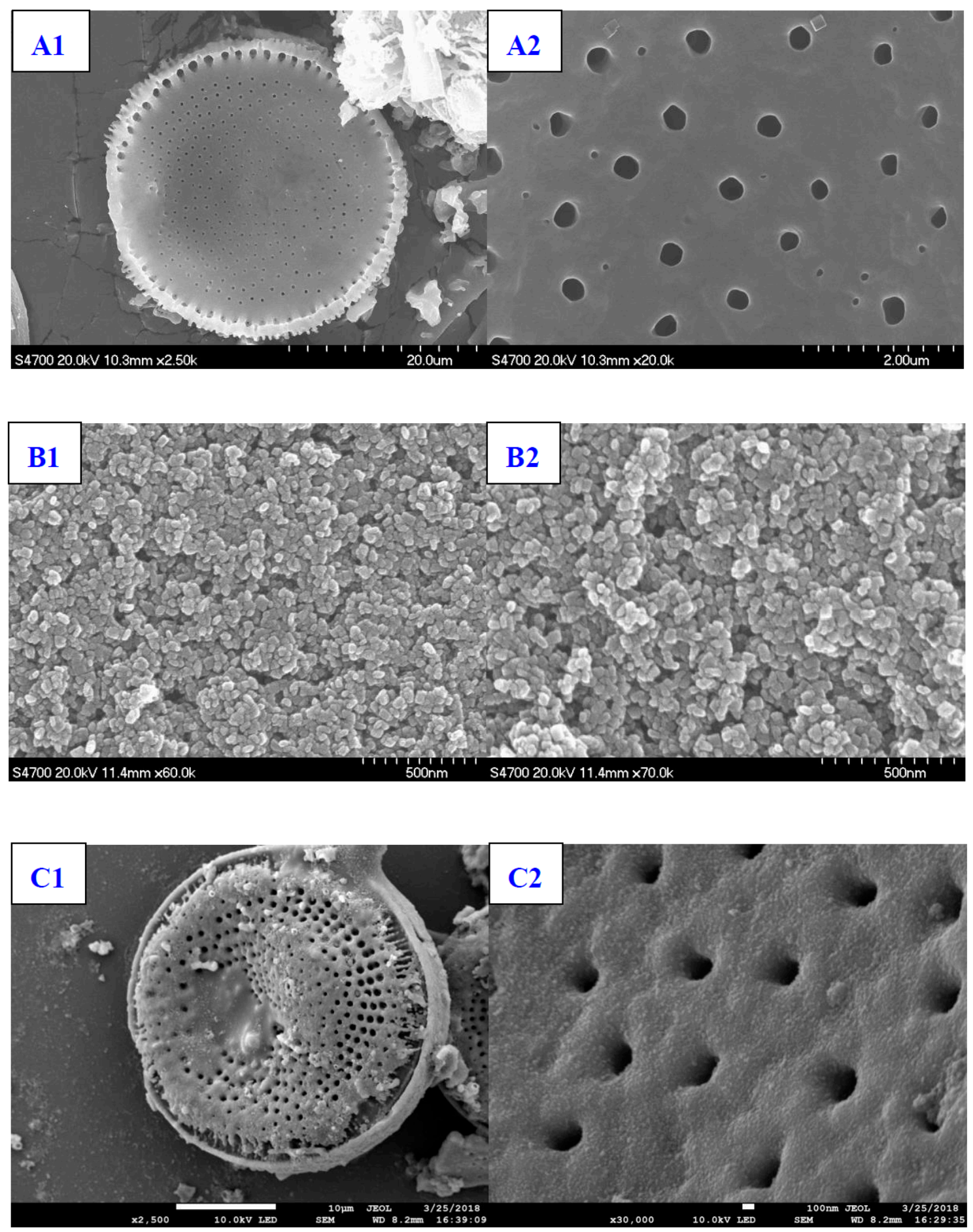

Figure 3. Cont. 

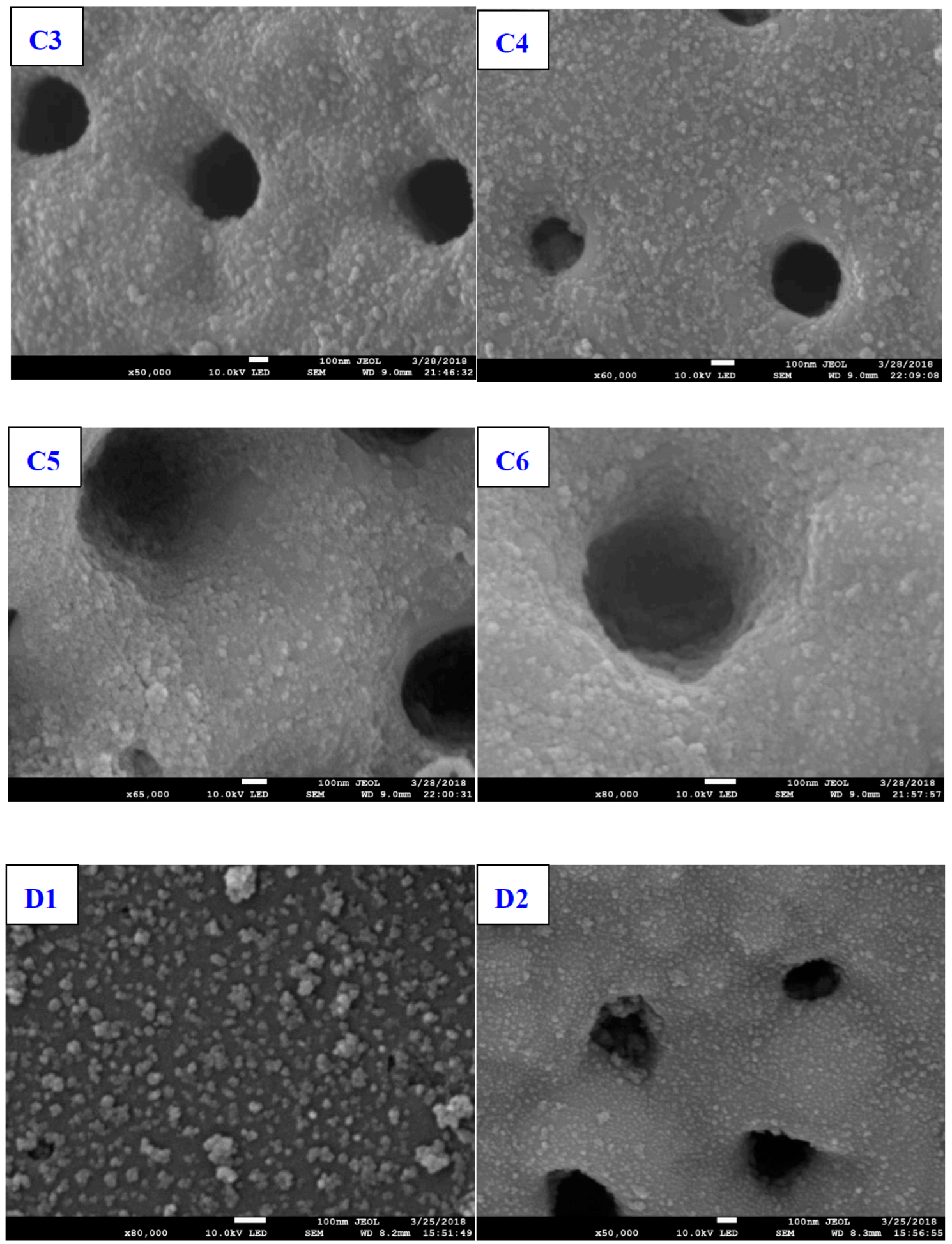

Figure 3. Cont. 

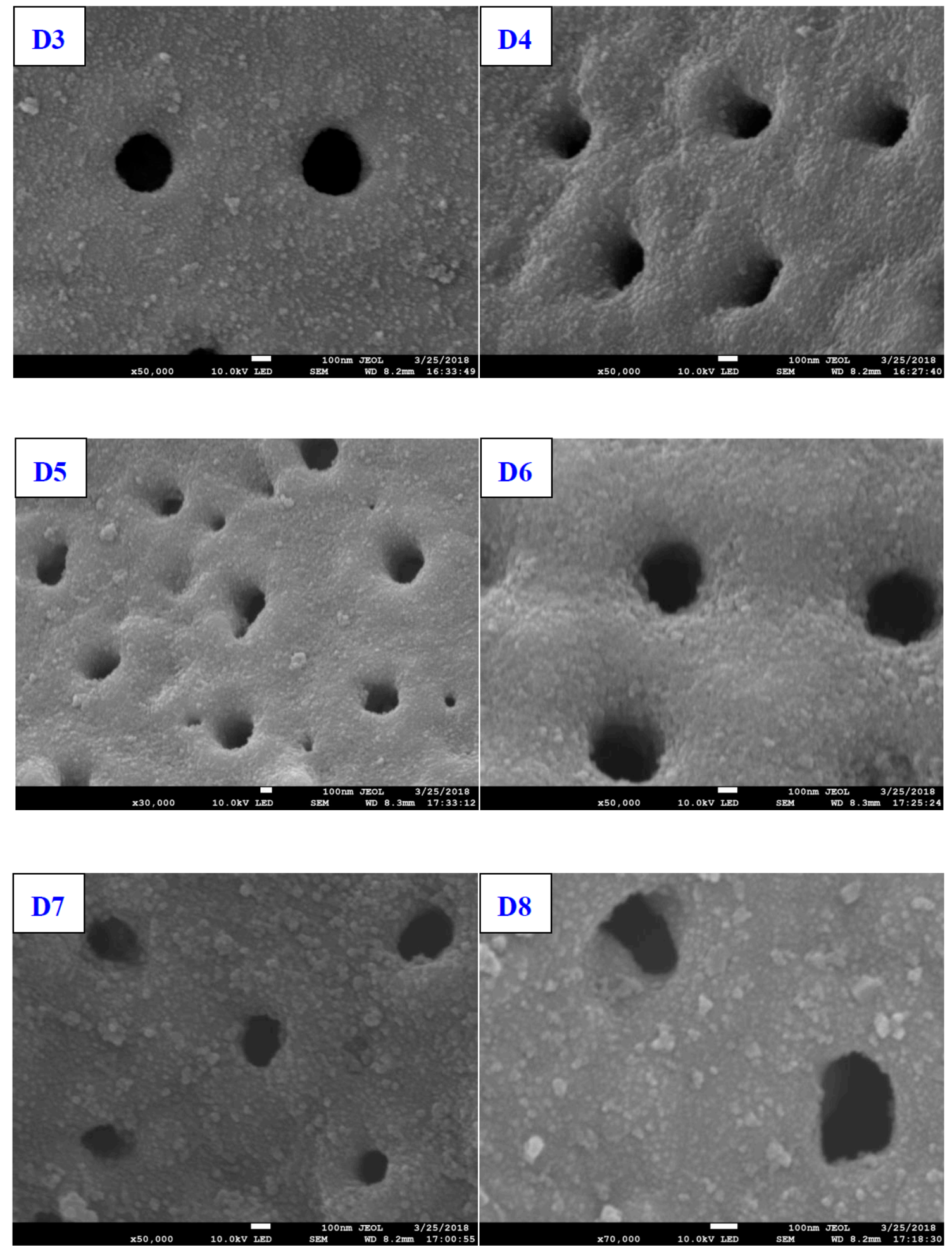

Figure 3. Cont. 

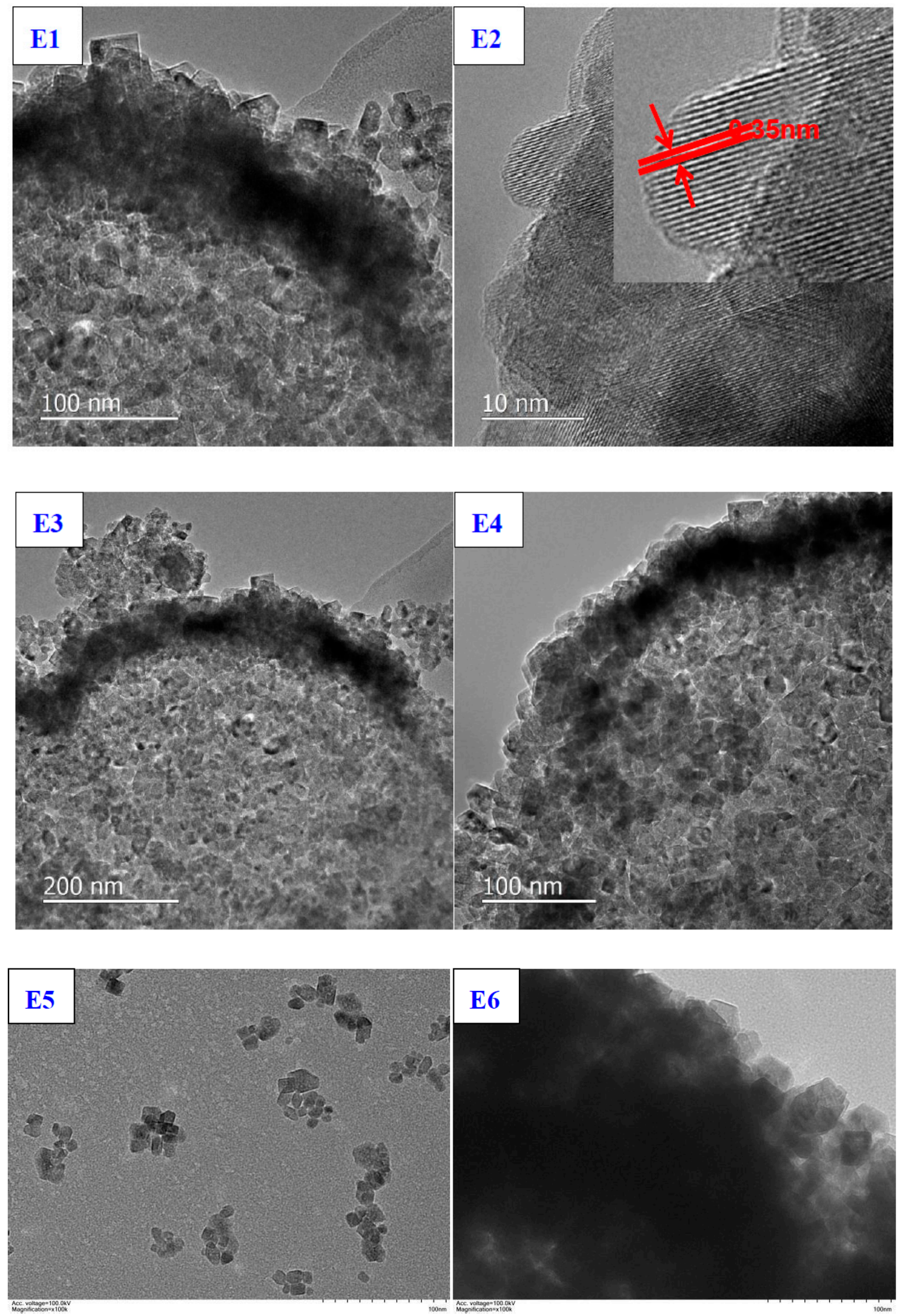

Figure 3. Cont. 


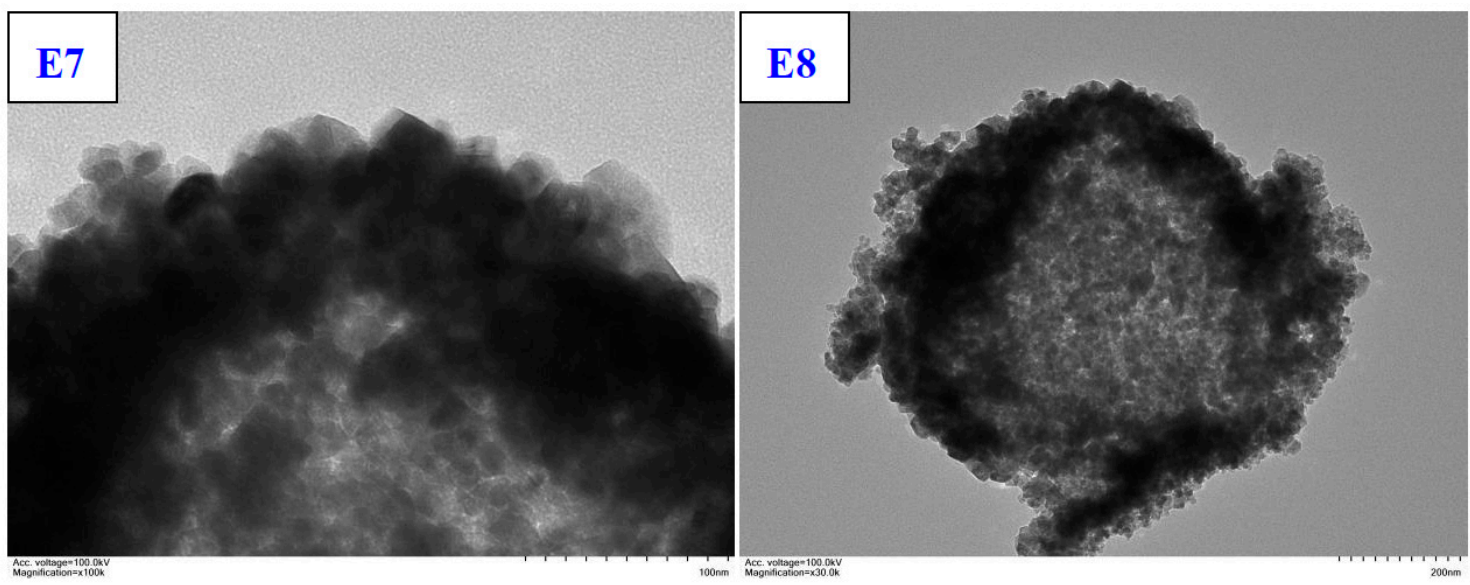

Figure 3. Scanning electron microscopy (SEM) images with different magnifications of (A1,A2) diatomite, (B1,B2) $\mathrm{TiO}_{2},(\mathbf{C 1}-\mathbf{C 6})$ 0.35 $\mathrm{TiO}_{2} @$ diatomite, (D1,D2) 0.30TiO $@$ diatomite, (D3,D4) 0.40TiO $@$ diatomite, (D5,D6) 0.45TiO $@$ @diatomite, and (D7,D8) 0.50TiO $@$ @diatomite. (E1-E4) High-resolution transmission electron microscopy (HRTEM) images of $0.35 \mathrm{TiO}_{2} @$ diatomite and (E5-E8) transmittance electron microscopy (TEM) images of $0.35 \mathrm{TiO}_{2} @$ diatomite.

\subsection{UV-Vis Diffuse Reflectance Spectra}

As shown in Figure 4, the UV-vis diffuse reflectance spectra of the catalysts were measured to study the optical properties of the samples [45]. Clearly, for pure $\mathrm{TiO}_{2}$, there is no absorption at above $400 \mathrm{~nm}$. However, the absorption intensity at approximately $400 \mathrm{~nm}$ is stronger for $\mathrm{XTiO}_{2} @$ diatomite than for pure $\mathrm{TiO}_{2}$ and diatomite, and the absorption (at above $400 \mathrm{~nm}$ ) of $0.35 \mathrm{TiO}_{2} @$ diatomite is the strongest among the $\mathrm{XTiO}_{2} @$ diatomites considered. It can also be seen that the catalyst of $\mathrm{TiO}_{2} @$ diatomite shows a slight red shift, suggesting that the catalyst of $\mathrm{TiO}_{2} @$ diatomite can be excited by the visible light and thus an increase in the photocatalytic activity of the catalyst.

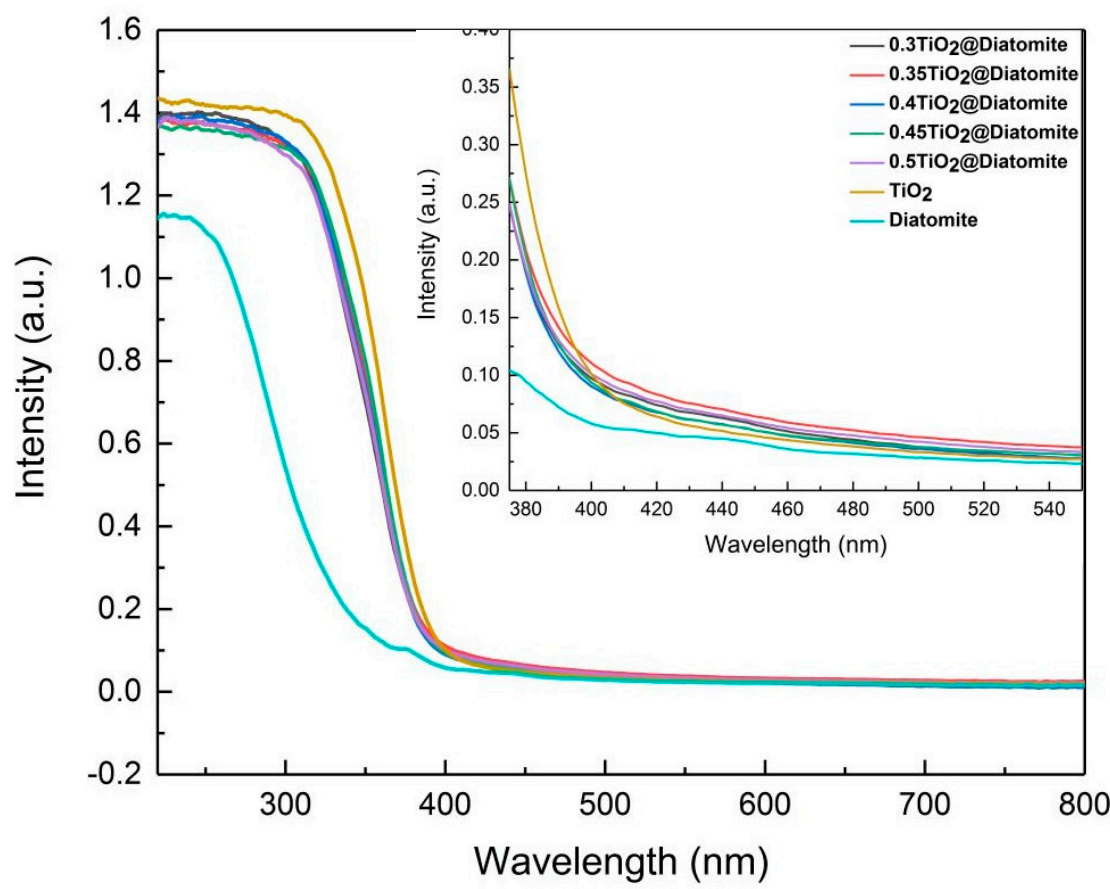

Figure 4. UV-visible diffuse reflectance adsorption spectra of the catalysts.

It can be seen from Figure 4 that pure $\mathrm{XTiO}_{2} @$ diatomite achieves absorption at 200-400 nm, although, according to previous studies [46], pure $\mathrm{SiO}_{2}$ has no absorption at $200-400 \mathrm{~nm}$. Therefore, 
the composite formed through a combination of the two with Si-O-Ti, which shows a red shift, may be attributed to the formation of this chemical bond, which reduces the energy and causes a slight red shift.

\subsection{BET Analysis}

The specific surface area and pore size distribution of the different catalysts were analyzed based on the nitrogen adsorption and desorption. The results are summarized in Table 2. The pure $\mathrm{TiO}_{2}$ nanoparticles have the largest specific surface area of approximately $115.74 \mathrm{~m}^{2} \mathrm{~g}^{-1}$. However, the specific surface area and pore volume of the pure diatomite are quite small, and thus the diatomite contributes less to the specific surface area of the $\mathrm{XTiO}_{2} @$ diatomites. In other words, the specific surface areas of the catalysts were not related to the $\mathrm{TiO}_{2}$ loadings. Therefore, the specific surface area and pore volume of the catalysts contribute little to their catalytic activity. As can be seen from Figure 5, the pure $\mathrm{TiO}_{2}$ exhibits type-IV adsorption curves with hysteresis loops between the $\mathrm{H} 1$ and $\mathrm{H} 2$ types; the diatomite shows IUPAC type-II isotherms, indicating the presence of micropores in the diatomite [47]; and the $\mathrm{TiO}_{2} @$ diatomite composites display type-IV isotherms with an overlap of the $\mathrm{H} 2$ and $\mathrm{H} 3$ hysteresis loops, which is related to the deposition of $\mathrm{TiO}_{2}$ nanoparticles on the surface of the diatomite.

Table 2. Surface and structural characterization of the catalysts.

\begin{tabular}{|c|c|c|c|}
\hline Sample & $\begin{array}{c}\text { BET Specific Surface } \\
\text { Area }\left(\mathrm{m}^{2} / \mathrm{g}\right)\end{array}$ & Pore Volume $\left(\mathrm{cm}^{3} / \mathrm{g}\right)$ & Average Pore Size (nm) \\
\hline Diatomite & 0.3202 & 0.002 & - \\
\hline Pure $\mathrm{TiO}_{2}$ & 115.7 & 0.257 & 8.8 \\
\hline 0.3TiO ${ }_{2} @$ diatomite & 20.6 & 0.044 & 8.5 \\
\hline 0.35TiO $\mathrm{Ti}_{2} @$ diatomite & 19.6 & 0.051 & 10.3 \\
\hline 0.4TiO $@$ @iatomite & 22.3 & 0.058 & 10.5 \\
\hline 0.45TiO $\mathrm{Ti}_{2} @$ diatomite & 21.7 & 0.056 & 10.4 \\
\hline 0.5TiO $@$ diatomite & 21.0 & 0.050 & 9.5 \\
\hline
\end{tabular}

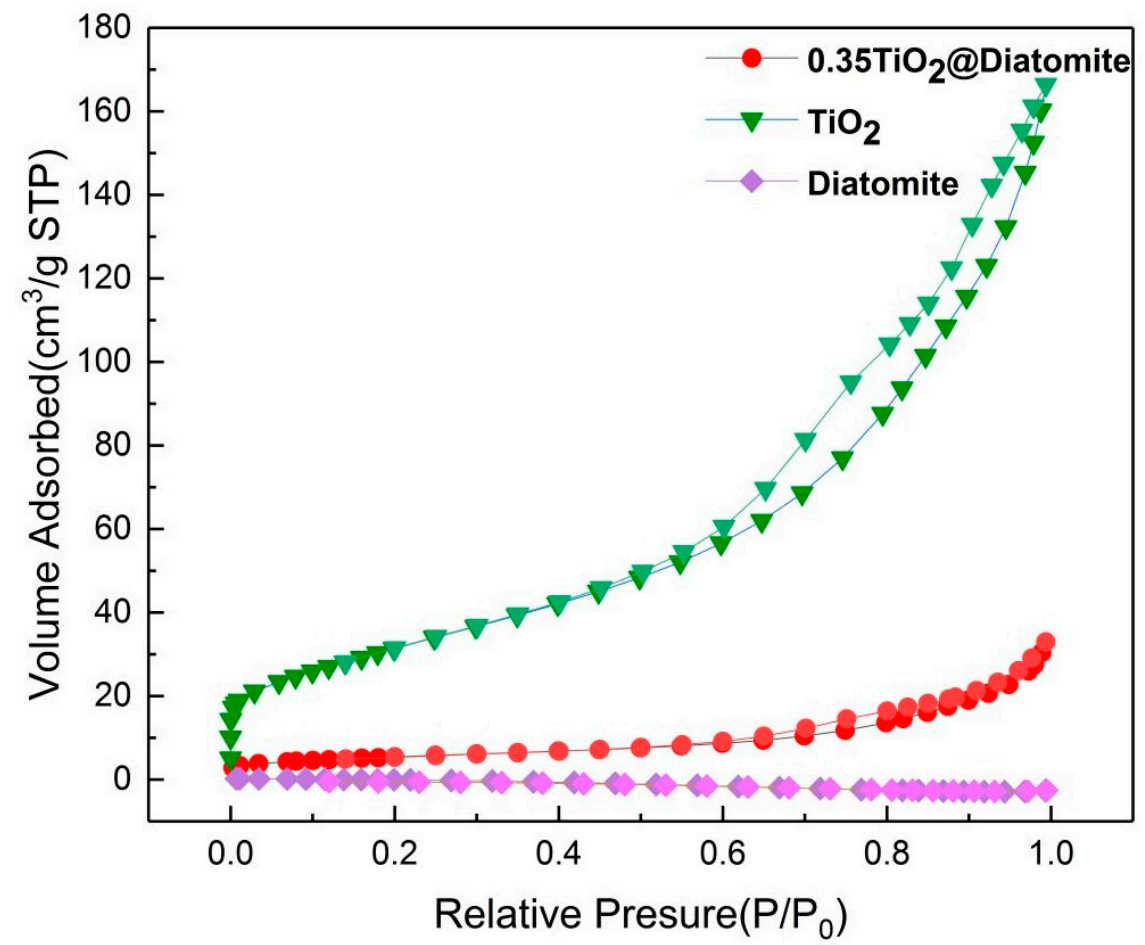

Figure 5. $\mathrm{N}_{2}$ adsorption-desorption isotherms of diatomite, $\mathrm{TiO}_{2}$, and $0.35 \mathrm{TiO}_{2} @$ diatomite. 


\subsection{Photoluminescence (PL) Spectra}

For the photocatalysts, apart from the surface area, the nanoparticle size, and the light absorption range, the electron-hole recombination property is also significant. PL can be used to evaluate the electron-hole recombination property. In other words, fluorescence will occur when electron-hole recombination arises [48]. Therefore, the rate of electron-hole recombination is inversely proportional to the fluorescence intensity, and thus a lower fluorescence intensity represents a lower electron and hole recombination rate and a higher photocatalytic activity $[49,50]$. As shown in Figure 6, the PL of different catalysts was measured at an excitation wavelength of $300 \mathrm{~nm}$. The strongest peaks of different catalysts all appear within approximately $400 \mathrm{~nm}$; however, their emission intensity varies significantly. For photocatalytic reactions, reducing the electron-hole recombination rate is an important goal. In other words, a low electron-hole recombination rate is favorable for a photocatalytic reaction. Among the catalysts applied, $0.35 \mathrm{TiO}_{2} @$ diatomite has the lowest emission intensity, indicating that it has the lowest electron-hole recombination rate and thus possesses a better photocatalytic performance. The reduction of the luminescence intensity may be related to the Ti-O-Si band and ascribed to the increased electron capture centering on the surface of the $\mathrm{TiO}_{2}$ nanoparticles, or an enhancement of the non-radiation-decay channels because of the $\mathrm{SiO}_{2}$ around the $\mathrm{TiO}_{2}$ nanoparticles.

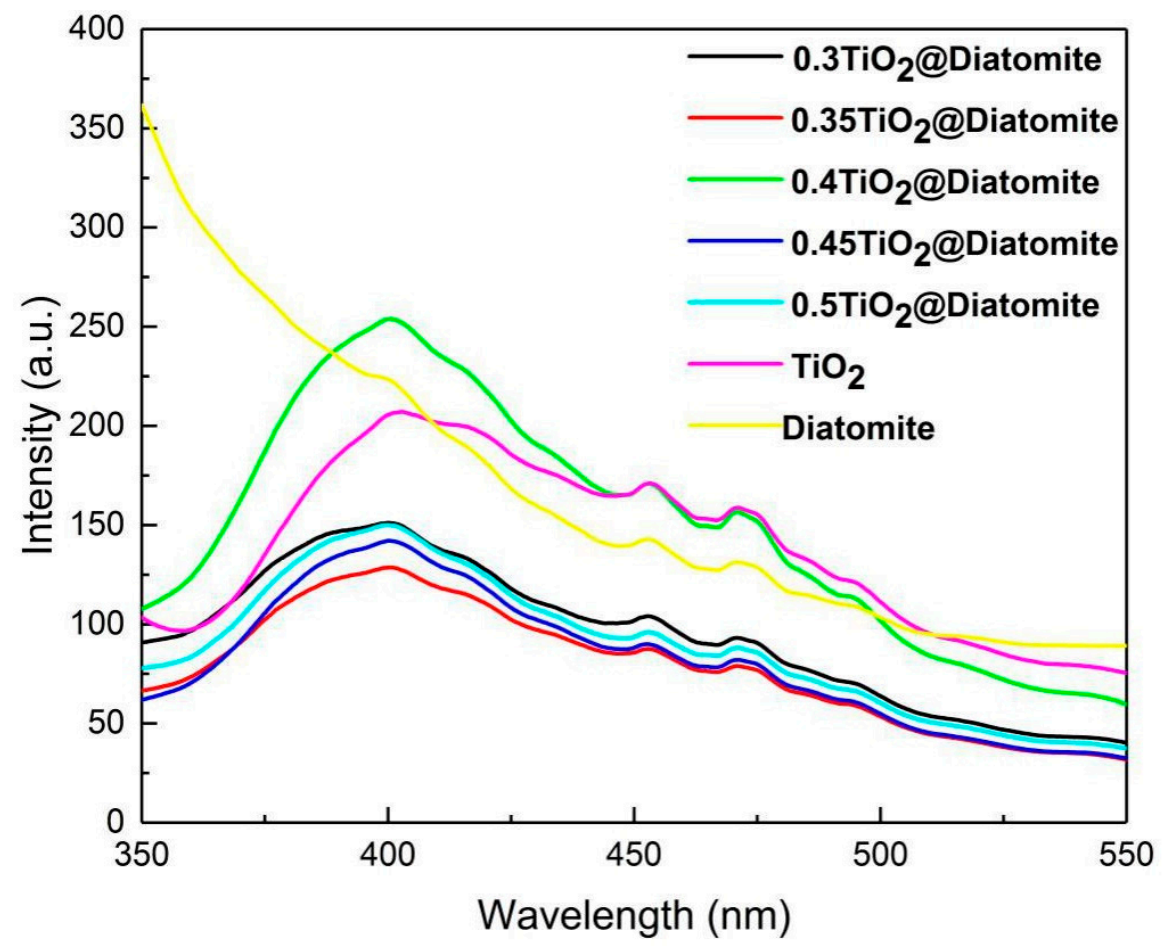

Figure 6. Photoluminescence (PL) spectra of $\mathrm{TiO}_{2}$, diatomite, and $\mathrm{XTiO}_{2} @$ diatomite.

Therefore, it can be concluded that the photocatalytic performance of $0.35 \mathrm{TiO}_{2} @$ diatomite may be better than that of the other catalysts. This result is consistent with that obtained from the UV-vis diffuse reflectance spectra, confirming that $0.35 \mathrm{TiO}_{2} @$ diatomite is the optimal catalyst.

\subsection{Photocatalytic Performance of Different Catalysts}

The $\mathrm{TiO}_{2}$ photocatalyst has a wide range of applications, such as air purification and sewage treatment. To evaluate the photocatalytic performance of different catalysts, a $5 \mathrm{~W}$ ultraviolet light source was used. Methylene blue (MB) was selected as the target pollutant to determine the optimal catalyst, and the optimal catalyst was then selected as the degradation catalyst for gaseous organic pollutants, such as acetone, benzene, methanol, and ethanol. Compared with pure $\mathrm{TiO}_{2}$, the $\mathrm{XTiO}_{2} @$ diatomite composite shows a relatively larger adsorption capacity for $\mathrm{MB}$ in spite of its 
lower specific surface area and pore volume. As shown in Figure 8a, minor differences appeared in different catalysts. With the catalyst of $0.35 \mathrm{TiO}_{2} @$ diatomite, the concentration of $\mathrm{MB}$ was nearly close to 0 within 90 min under UV light irradiation, and thus the degradation rate was faster than in the other similar photocatalysts. Clearly, 0.35TiO $@$ @iatomite (recorded as the optimal catalyst) showed the highest degradation rate for the photocatalytic degradation of MB. The MB degradation efficiency of pure diatomite is shown in Figure 8a, in which the concentration of MB remains almost unchanged as the irradiation time increases, indicating that the photocatalytic activity of $\mathrm{TiO}_{2} @$ diatomite is weak in the absence of $\mathrm{TiO}_{2}$, and that the photocatalytic activity of $\mathrm{XTiO}_{2} @$ diatomite is better than that of pure $\mathrm{TiO}_{2}$, suggesting a synergy effect between $\mathrm{TiO}_{2}$ and diatomite (which may benefit from the formation of Si-O-Ti bonds). Because a Si-O-Ti bond can be formed when the surface of diatomite is covered with hydroxyl and silanol, this special structure allows $\mathrm{TiO}_{2}$ to laboriously combine with diatomite, and further enhances its dispersibility, thereby significantly increasing its photocatalytic performance [46]. Among the types of $\mathrm{XTiO}_{2} @$ diatomite applied, the photocatalytic activity of $0.35 \mathrm{TiO}_{2} @$ diatomite was better than that of the other catalysts. In addition, the photocatalytic activity of $\mathrm{TiO}_{2} @$ diatomite is not simply promoted by the increasing load ratio of $\mathrm{TiO}_{2}$ to diatomite. By contrast, excessive loading amounts of $\mathrm{TiO}_{2}$ can in turn reduce the photocatalytic capability. This was confirmed through 0.35 $\mathrm{TiO}_{2} @$ diatomite, which exhibited the highest performance. This can be explained by the fact that excessive $\mathrm{TiO}_{2}$ causes an agglomeration of $\mathrm{TiO}_{2}$ on the surface of the diatomite, and thus reduces the photocatalytic performance of $\mathrm{TiO}_{2} @$ diatomite. This result agrees with the results obtained from the UV-vis diffuse reflectance spectra, PL spectra, and degree of aggregation shown on the SEM images. Therefore, 0.35 $\mathrm{TiO}_{2} @$ diatomite was selected for the degradation experiment of the following gaseous organic pollutants.

Figure $8 b, c$ show the degradation results of gaseous acetone and gaseous benzene, respectively. The gas concentration was controlled by adding $1 \mathrm{~mL}$ of saturated gas at room temperature to each of the six headspace bottles with three capacities $(100,200$, and $500 \mathrm{~mL})$, which were labeled as 100 $\mathrm{mL}(1), 100 \mathrm{~mL}(2), 200 \mathrm{~mL}(1), 200 \mathrm{~mL}(2), 500 \mathrm{~mL}(1)$, and $500 \mathrm{~mL}(2)$. In this experiment, bottles with the volumes shown in Figure $8 \mathrm{c}$ were used to degrade the gases, bottles of the same volume were used in repeated experiments three times, and the data were averaged to verify the accuracy. As can be seen from Figure 8b, under UV-Vis light irradiation, the optimal catalyst showed an excellent photocatalytic performance for gaseous acetone at different concentrations. In the experiment on the degradation of gaseous acetone, the concentration of gaseous acetone reached close to 0 in 90 min under UV-Vis light irradiation. This means that gaseous acetone can be completely decomposed in only $90 \mathrm{~min}$ at a fast rate, and slow decomposition can be completely achieved within $120 \mathrm{~min}$. This is because the concentration of acetone is so high that it cannot be completely degraded within $90 \mathrm{~min}$. In other words, after $90 \mathrm{~min}$ of irradiation, the degradation rate of $0.35 \mathrm{TiO}_{2} @$ diatomite for gaseous acetone reaches up to $100 \%$, which is greater than in most other studies [51]. From Figure $8 \mathrm{c}$, it can be seen that gaseous benzene is degraded within $90 \mathrm{~min}$. However, most of the gaseous benzene with different concentrations cannot be completely degraded. One possible reason for this is that the structure of a benzene molecule is extremely stable and difficult to break. Another possible reason is that the concentration of gaseous benzene is too high to be completely degraded. In this study, only two gaseous organic pollutants were investigated. In the future, we will study the degradation of the catalyst under other gaseous organic pollutants (such as methanol, ethanol, propanol, formaldehyde, and acetaldehyde) and summarize whether the effects on the polar and non-polar organics are identical. 


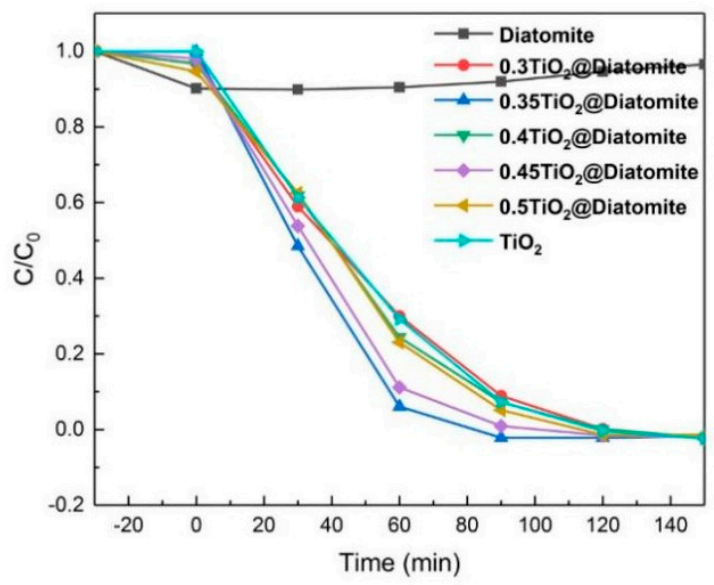

(a)

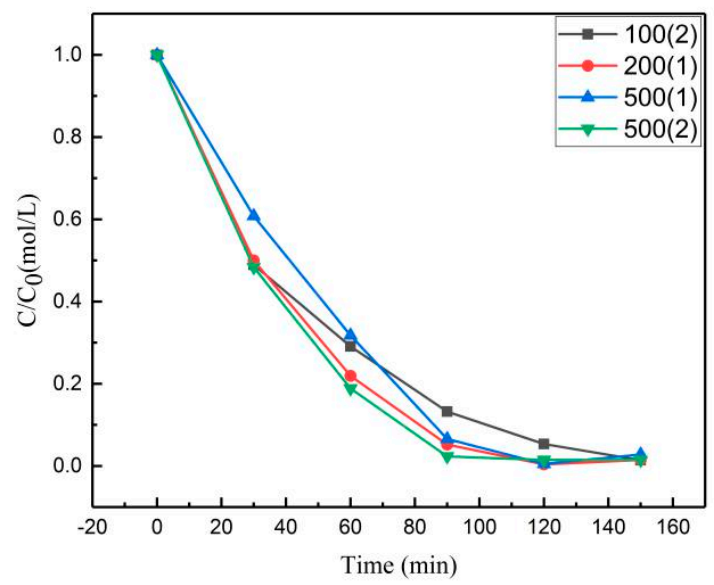

(b)

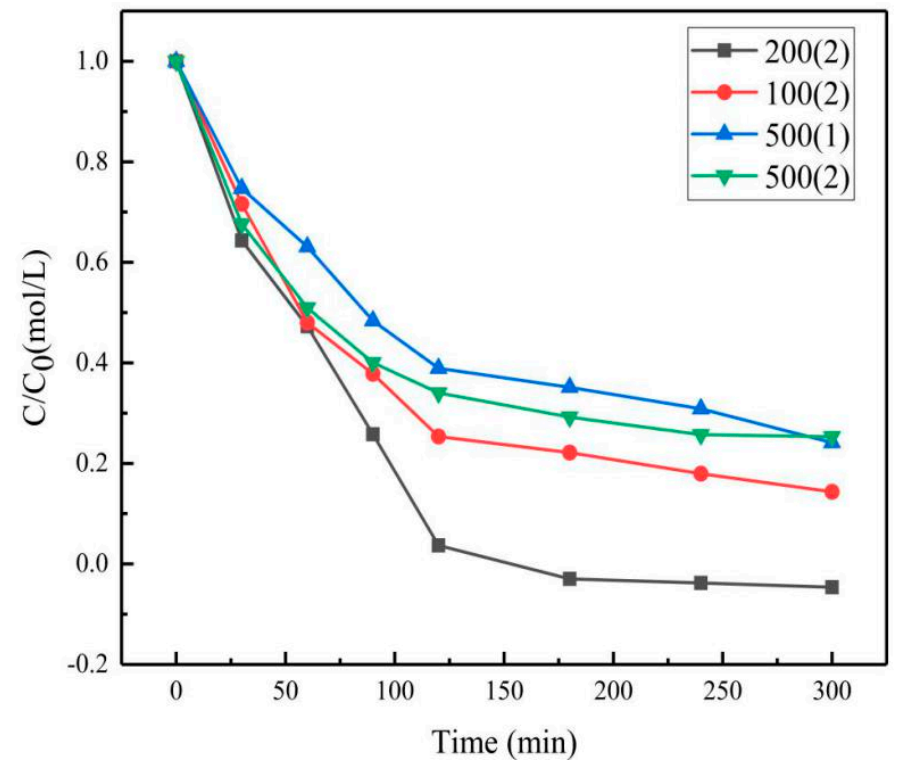

(c)

Figure 7. (a) Plots of the methylene blue (MB) photodegradation over various catalysts under UV irradiation. (b) Plots of the photodegradation of various concentrations of gaseous acetone over 0.35TiO $\mathrm{T}_{2} @$ diatomite under UV-Vis light irradiation. (c) Plots of the photodegradation of benzene at various concentrations over $0.35 \mathrm{TiO}_{2} @$ diatomite under UV-Vis light irradiation.

\section{Experimental Section}

\subsection{Chemicals and Materials}

Diatomite (Macklin, Shanghai, China), titanium tetrachloride $\left(\mathrm{TiCl}_{4}\right.$, analytical reagent, Adamas, Beijing, China), absolute ethanol (analytical reagent, Tianjin Damao Chemical Reagents Factory, Tianjin, China), benzene (analytical reagent, Tianjin Damao Chemical Reagents Factory, Tianjin, China), acetone (analytical reagent, Tianjin Damao Chemical Reagents Factory, Tianjin, China), and deionized water were used for the synthesis of $\mathrm{TiO}_{2}$ and diatomite/TiO 2 . During the process of synthesizing diatomite $/ \mathrm{TiO}_{2}$, the only difference from $\mathrm{TiO}_{2}$ is that a certain amount of diatomite is added to the synthetic process for $\mathrm{TiO}_{2}$. All the reagents listed were used as purchased and without further treatment.

\subsection{Catalyst Preparation}

The $\mathrm{TiO}_{2} @$ diatomite was prepared using a facile solvothermal method applying absolute ethanol as a solvent. Pure ethanol $(50 \mathrm{~mL})$ was transferred into a three-necked flask $(250 \mathrm{~mL})$ placed in an ice 
bath and stirred for $30 \mathrm{~min}$. Then, $0.5 \mathrm{~mL}$ of deionized water $(0.5 \mathrm{~mL})$ was added. After $5 \mathrm{~min}, \mathrm{TiCl}_{4}(2$ $\mathrm{mL})$ was added dropwise. The mixture was stirred until it became a transparent light-yellow solution. This solution was transferred to a dry Teflon-lined stainless-steel autoclave $(100 \mathrm{~mL})$ containing a certain amount of diatomite, and stirred evenly. The resulting mixture was then kept at $200{ }^{\circ} \mathrm{C}$ for $12 \mathrm{~h}$ in an oven. After cooling to room temperature, the white precipitates were filtered off, and washed with ethanol and deionized water several times until the $\mathrm{pH}$ of the filtrate reached approximately 7 . The chlorine was also removed through the washing process. The collected precipitates were dried at $80^{\circ} \mathrm{C}$ for $10 \mathrm{~h}$ in the oven to afford $\mathrm{TiO}_{2} @$ diatomite. Detailed steps regarding the synthesis of $\mathrm{TiO}_{2} @$ diatomite are also shown in Figure ??. For convenience, the catalysts are denoted as $\mathrm{XTiO}_{2} @$ diatomite, where $\mathrm{X}$ represents the mass ratio of $\mathrm{TiO}_{2}$ to diatomite (because diatomite cannot be expressed in moles). The pure $\mathrm{TiO}_{2}$ was prepared according to the above procedure, except with the addition of diatomite steps.

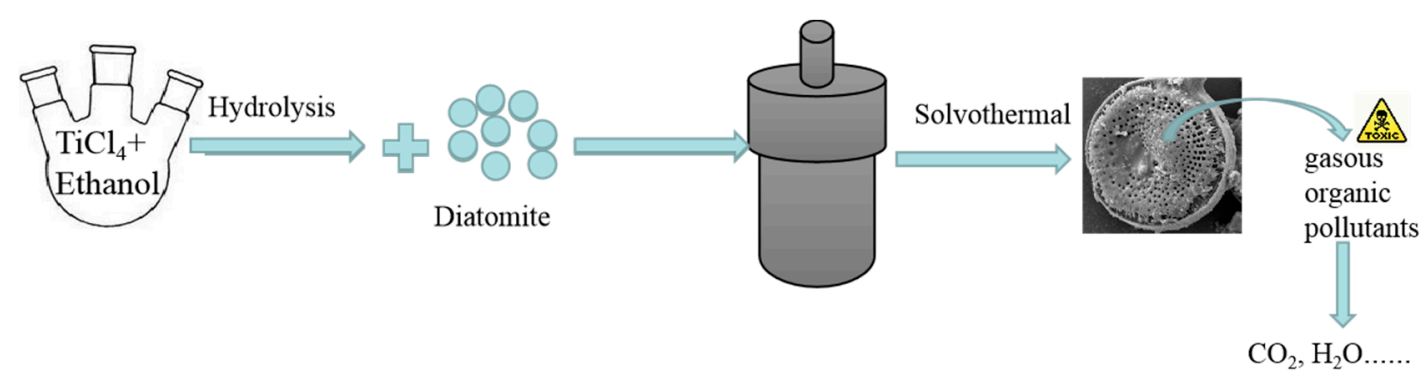

Figure 8. Synthesis procedure for $\mathrm{XTiO}_{2} @$ diatomite catalysts.

\subsection{Characterization}

The catalysts were characterized based on X-ray diffraction patterns (XRD, Ultiam IV) recorded using $\mathrm{Cu} \mathrm{K} \alpha$ radiation at a scan rate of $5^{\circ} / \mathrm{min}$. Their microstructures were observed using field-emission SEM (JEOL-JSM-7800F (Tokyo, Japan) with an energy dispersive spectrometer and S-4700 at an acceleration voltage of $20 \mathrm{KV}$ ), TEM (Hitachi-HT7700 (Tokyo, Japan) at an acceleration voltage of $120 \mathrm{KV}$ and JEM-ARM-200F), and HRTEM (JEOL, JEM-ARM200F, Tokyo, Japan). The specific surface area and pore size distribution of the different catalysts were determined using a Brunauer-Emmett-Teller (BET) instrument with nitrogen adsorption at $77 \mathrm{~K}$ (Micrometrics ASAP 2020, Georgia, USA). In addition, the ultraviolet-visible spectrophotometer (Shimadzu UV-3600, Tokyo, Japan) was used to analyze the UV-vis diffuse reflectance spectra of the prepared catalysts. Moreover, the electron hole recombination rate was measured using a photoluminescence spectrometer (FL-7000, Hitachi, Tokyo, Japan) to evaluate the photocatalytic activity.

\subsection{Evaluation of Photocatalytic Activity}

The photocatalytic activities of different catalysts were initially evaluated based on the degradation of MB under UV-light irradiation at ambient temperature [52]. During this process, the catalyst $(0.05$ g) was dispersed in an $\mathrm{MB}$ solution (10 of $\mathrm{MB}(50 \mathrm{mg} / \mathrm{mL}, 30 \mathrm{~mL})$ ) in a Petri dish. A portion of MB solution was taken every $30 \mathrm{~min}$ for measurements using an ultraviolet-visible spectrophotometer. The degradation rate was determined by monitoring the change in concentration of the MB over time using an ultraviolet-visible spectrophotometer (Shimadzu UV-3600). The catalyst with the highest degradation rate was chosen for degradation of the different gaseous organic pollutants, including acetone and benzene. These degradation processes were carried out in sealed headspace bottles with different volumes $(100,200$, and $500 \mathrm{~mL})$. The concentration of gas was controlled by adding equal volumes of saturated gas to different volumes of sealed headspace bottles (to the best of our knowledge, at the same temperature, the concentration of saturated gas is constant). The specific experimental details are similar to those of the process of MB degradation described above [52], except that the MB solution was replaced with gaseous phase organic pollutants. The details of the experiment are as follows: A catalyst $(0.05 \mathrm{~g})$ was added to each of the headspace bottles, and $1 \mathrm{~mL}$ of saturated gaseous 
phase pollutants at room temperature was transferred to the sealed headspace bottles using a gas chromatography syringe with a capacity of $2.5 \mathrm{~mL}$. In addition, the initial concentrations of gaseous acetone and benzene in the 100, 200, and $500 \mathrm{~mL}$ headspace bottles were approximately $2.95 \times 10^{-3}$, $1.63 \times 10^{-3}$, and $6.85 \times 10^{-4} \mathrm{~mol} / \mathrm{L}$, respectively. A xenon lamp $(30 \mathrm{~W})$ was adopted as a light source during the photocatalytic degradation process. The headspace bottle was placed under the light, and the bottle was directly irradiated. The whole process was degraded at room temperature. Throughout the degradation process, no heating and any agitation were used. Simultaneously, gases were taken every $30 \mathrm{~min}$ and the corresponding concentrations of organic gaseous pollutants were determined using gas chromatography-mass spectrometry (GC-MS). In addition, the degradation reaction of the organic gaseous pollutants was kept at ambient temperature. Four sealed headspace bottles of each gas were used for gaseous pollutant degradation. All reactions were repeated three times in parallel.

\section{Conclusions}

In conclusion, we successfully prepared a series of $\mathrm{TiO}_{2} @$ diatomite catalysts using a facile solvothermal method applying anhydrous ethanol as a solvent for the removal of VOCs. The XRD patterns showed that $\mathrm{TiO}_{2}$ in the catalyst is in an anatase phase, and the introduction of diatomite has no effect on the crystal structure of $\mathrm{TiO}_{2}$. SEM and TEM images indicated that the size of the $\mathrm{TiO}_{2}$ nanoparticles is approximately $10-15 \mathrm{~nm}$, and the morphologies of most of the $\mathrm{TiO}_{2}$ nanoparticles are square-like. In addition, for the $\mathrm{TiO}_{2} @$ diatomite, the $\mathrm{TiO}_{2}$ nanoparticles are uniformly immobilized on the diatomite. Based on photocatalytic activity tests, $0.35 \mathrm{TiO}_{2} @$ diatomite (with a $\mathrm{TiO}_{2}$ to diatomite mass ratio of 0.35 ) displayed higher photocatalytic activity compared with that at other ratios, pure $\mathrm{TiO}_{2}$, and pure diatomite. This result is consistent with the characterization results of the UV-vis diffuse reflectance spectra and PL spectra. The photocatalytic performance and GC-MS test results showed that $0.35 \mathrm{TiO}_{2} @$ diatomite can be used to effectively remove acetone and benzene. In addition, both $\mathrm{TiO}_{2}$ and diatomite are low-cost, non-toxic, harmless, and stable. Therefore, a $\mathrm{TiO}_{2} @$ diatomite catalyst could potentially be applied in the area of building construction and interior decoration.

Author Contributions: Conceptualization, X.L. \& J.Y.; Methodology, X.L.; Software, X.L.; \& Q.Y. \& B.Y.; Formal Analysis, X.L.; Data curation, X.L. \& J.Y.; Writing-Original draft preparation, X.L.; Writing-Review \& Editing, X.L. \& J.Y.; Visualization, X.L. \& J.Y. \& Y.H.; Supervision, J.Y.; Funding acquisition, J.Y. All authors have read and agreed to the published version of the manuscript.

Funding: This research received no external funding.

Acknowledgments: The authors express their gratitude to the Analysis and Test Center of Beijing University of Chemical Technology for the received help.

Conflicts of Interest: The authors declare no conflict of interest.

\section{References}

1. Knudsen, H.N.; Kjaer, U.D.; Nielsen, P.A.; Wolkoff, P. Sensory and chemical characterization of voc emissions from building products: Impact of concentration and air velocity. Atmos. Environ. 1999, 33, 1217-1230. [CrossRef]

2. Salthammer, T. Emission of volatile organic compounds from furniture coatings. Indoor Air 1996, 7, $189-197$. [CrossRef]

3. Wolkoff, P. Volatile organic compounds sources, measurements, emissions, and the impact on indoor air quality. Indoor Air 1995, 5, 5-73. [CrossRef]

4. Meininghaus, R.; Gunnarsen, L.; Knudsen, H.N. Diffusion and sorption of volatile organic compounds in building materials-Impact on indoor air quality. Environ. Sci. Technol. 2000, 34, 3101-3108. [CrossRef]

5. Dai, H.; Jing, S.; Wang, H. VOC characteristics and inhalation health risks in newly renovated residences in Shanghai, China. Sci. Total Environ. 2017, 577, 73-83. [CrossRef]

6. Bentayeb, M.; Simoni, M.; Norback, D.; Baldacci, S.; Maio, S.; Viegi, G.; Annesi-Maesano, I. Indoor air pollution and respiratory health in the elderly. J. Environ. Sci. Health A 2013, 48, 1783-1789. [CrossRef] 
7. Ye, D.; Klein, M.; Chang, H.H.; Sarnat, J.A.; Mulholland, J.A.; Edgerton, E.S.; Winquist, A.; Tolbert, P.E.; Sarnat, S.E. Estimating acute cardiorespiratory effects of ambient volatile organic compounds. Epidemiology (Camb. Mass.) 2017, 28, 197. [CrossRef]

8. World Health Organization. Burden of Disease from the Joint Effects of Household and Ambient Air Pollution for 2016; Social and Environmental Determinants of Health Department: Geneva, Switzerland, 7 November 2018.

9. Lam, R.C.W.; Leung, M.K.H.; Leung, D.Y.C.; Vrijmoed, L.L.P.; Yam, W.C.; Ng, S.P. Visible-light-assisted photocatalytic degradation of gaseous formaldehyde by parallel-plate reactor coated with $\mathrm{Cr}$ ion-implanted $\mathrm{TiO}_{2}$ thin film. Sol. Energy. Mat. Sol. C. 2007, 91, 54-61. [CrossRef]

10. Jeong, J.; Sekiguchi, K.; Sakamoto, K. Photochemical and photocatalytic degradation of gaseous toluene using short-wavelength uv irradiation with $\mathrm{TiO}_{2}$ catalyst: Comparison of three uv sources. Chemosphere 2004, 57, 663-671. [CrossRef]

11. Higashimoto, S.; Tanihata, W.; Nakagawa, Y.; Azuma, M.; Ohue, H.; Sakata, Y. Effective photocatalytic decomposition of voc under visible-light irradiation on n-doped $\mathrm{TiO}_{2}$ modified by vanadium species. Appl. Catal. A Gen. 2008, 340, 98-104. [CrossRef]

12. Azzouz, I.; Habba, Y.G.; Capochichi-Gnambodoe, M.; Marty, F.; Vial, J.; Leprince-Wang, Y.; Bourouina, T. Zinc oxide nano-enabled microfluidic reactor for water purification and its applicability to volatile organic compounds. Microsyst. Nanoeng. 2018, 4,1-7. [CrossRef]

13. Ghorbani Shahna, F.; Bahrami, A.; Ebrahimi, H. The hybrid effect of non-thermal plasma and activated carbon-zinc oxide nanocomposite on the removal of volatile organic compounds in air. Iran Occup. Health 2017, 14, 24-13.

14. Meng, F.; Zheng, H.; Chang, Y.; Zhao, Y.; Li, M.; Wang, C.; Sun, Y.; Liu, J. One-step synthesis of Au/SnO $2 / \mathrm{RGO}$ nanocomposites and their VOC sensing properties. IEEE. Trans. Nanotechnol. 2018, 17, 212-219. [CrossRef]

15. Kaur, M.; Kumar, A.G. Synthesis and Characterization of Mesoporous $\mathrm{SnO}_{2}$ Photocatalyst for Degradation of Dye and Volatile Organic Compound. Ph.D. Thesis, 2016.

16. Wang, L.; Xu, X.; Wang, Y.; Wang, X.; Shi, F.-N. Sulfur vacancy-rich CdS loaded on filter paper-derived 3D nitrogen-doped mesoporous carbon carrier for photocatalytic VOC removal. Inorg. Chem. Front. 2018, 5, 1470-1476. [CrossRef]

17. Zhou, H.; Wen, Z.; Liu, J.; Ke, J.; Duan, X.; Wang, S. Z-scheme plasmonic Ag decorated $\mathrm{WO}_{3} / \mathrm{Bi}_{2} \mathrm{WO}_{6}$ hybrids for enhanced photocatalytic abatement of chlorinated-VOCs under solar light irradiation. Appl. Catal. B Environ. 2019, 242, 76-84. [CrossRef]

18. Šuligoj, A.; Štangar, U.L.; Ristić, A.; Mazaj, M.; Verhovšek, D.; Tušar, N.N. $\mathrm{TiO}_{2}-\mathrm{SiO}_{2}$ films from organic-free colloidal $\mathrm{TiO}_{2}$ anatase nanoparticles as photocatalyst for removal of volatile organic compounds from indoor air. Appl. Catal. B Environ. 2016, 184, 119-131. [CrossRef]

19. Weon, S.; Choi, E.; Kim, H.; Kim, J.Y.; Park, H.J.; Kim, S.M.; Kim, W.; Choi, W. Active $\{001\}$ facet exposed $\mathrm{TiO}_{2}$ nanotubes photocatalyst filter for volatile organic compounds removal: From material development to commercial indoor air cleaner application. Environ. Sci. Technol. 2018, 52, 9330-9340. [CrossRef]

20. Haghighatmamaghani, A.; Haghighat, F.; Lee, C.S. Performance of various commercial $\mathrm{TiO}_{2}$ in photocatalytic degradation of a mixture of indoor air pollutants: Effect of photocatalyst and operating parameters. Sci. Technol. Built. Environ. 2019, 25, 600-614. [CrossRef]

21. Li, F.B.; Li, X.Z.; Ao, C.H.; Lee, S.C.; Hou, M.F. Enhanced photocatalytic degradation of VOCs using $\mathrm{Ln}^{3+}-\mathrm{TiO}_{2}$ catalysts for indoor air purification. Chemosphere 2005, 59, 787-800. [CrossRef]

22. Tidahy, H.L.; Siffert, S.; Lamonier, J.F.; Zhilinskaya, E.A.; Aboukais, A.; Yuan, Z.-Y.; Vantomme, A.; Su, B.-L.; Canet, X.; De Weireld, G.; et al. New Pd/hierarchical macro-mesoporous $\mathrm{ZrO}_{2}, \mathrm{TiO}_{2}$ and $\mathrm{ZrO}_{2}-\mathrm{TiO}_{2}$ catalysts for VOCs total oxidation. Appl. Catal. A Gen. 2006, 310, 61-69. [CrossRef]

23. Pham, T.D.; Lee, B.K. Selective removal of polar VOCs by novel photocatalytic activity of metals co-doped $\mathrm{TiO}_{2} / \mathrm{PU}$ under visible light. Chem. Eng. J. 2017, 307, 63-73. [CrossRef]

24. Ochiai, T.; Tago, S.; Hayashi, M.; Tawarayama, H.; Hosoya, T.; Fujishima, A. $\mathrm{TiO}_{2}$-impregnated porous silica tube and its application for compact air-and water-purification units. Catalysts 2015, 5, 1498-1506. [CrossRef]

25. Shayegan, Z.; Lee, C.S.; Haghighat, $\mathrm{F}$. $\mathrm{TiO}_{2}$ photocatalyst for removal of volatile organic compounds in gas phase-A review. Chem. Eng. J. 2018, 334, 2408-2439. [CrossRef]

26. Ji, J.; Xu, Y.; Huang, H.; He, M.; Liu, S.; Liu, G.; Xie, R.; Feng, Q.; Shu, Y.; Zhan, Y. Mesoporous TiO 2 under VUV irradiation: Enhanced photocatalytic oxidation for VOCs degradation at room temperature. Chem. Eng. J. 2017, 327, 490-499. [CrossRef] 
27. Ao, C.H.; Lee, S.C.; Mak, C.L.; Chan, L.Y. Photodegradation of volatile organic compounds (VOCs) and NO for indoor air purification using $\mathrm{TiO}_{2}$ : Promotion versus inhibition effect of NO. Appl. Catal. B Environ. 2003, 42, 119-129. [CrossRef]

28. Hwang, J.Y.; Kim, H.M.; Lee, S.K. High-Energy, High-Rate, Lithium-Sulfur Batteries: Synergetic Effect of Hollow $\mathrm{TiO}_{2}$-Webbed Carbon Nanotubes and a Dual Functional Carbon-Paper Interlayer. Adv. Energy. Mater. 2016, 6, 1501480. [CrossRef]

29. Zhu, S.R.; Wu, M.K.; Zhao, W.N.; Yi, F.Y.; Tao, K.; Han, L. Fabrication of heterostructured $\mathrm{BiOBr} / \mathrm{Bi}_{24} \mathrm{O}_{3} 1 \mathrm{Br} 10 / \mathrm{TiO}_{2}$ photocatalyst by pyrolysis of $\mathrm{MOF}$ composite for dye degradation. J. Solid State Chem. 2017, 255, 17-26. [CrossRef]

30. Yan, L.; Gu, Y.; Han, L.; Wang, P.; Li, H.; Yan, T.; Kuboon, S.; Shi, L.; Zhang, D. Dual Promotional Effects of $\mathrm{TiO}_{2}$-Decorated Acid-Treated $\mathrm{MnO}$ x Octahedral Molecular Sieve Catalysts for Alkali-Resistant Reduction of NOx. ACS. Appl. Mater. Interfaces 2019, 11, 11507-11517. [CrossRef]

31. Li, M.; Lu, B.; Ke, Q.F.; Guo, Y.J.; Guo, Y.P. Synergetic effect between adsorption and photodegradation on nanostructured $\mathrm{TiO}_{2}$ /activated carbon fiber felt porous composites for toluene removal. J. Hazard. Mater. 2017, 333, 88-98. [CrossRef]

32. Zuo, R.; Du, G.; Zhang, W.; Liu, L.; Liu, Y.; Mei, L. Photocatalytic degradation of methylene blue using $\mathrm{TiO}_{2}$ impregnated diatomite. Adv. Mater. Sci. Eng. 2014, 2014, 170148. [CrossRef]

33. PENNY Crossley. Clarifying matters-world diatomite reviewed. Ind. Miner. 2000, 390, 119-141.

34. Al-Degs, Y.; Khraisheh, M.A.M.; Tutunji, M.F. Sorption of Lead Ions on Diatomite and Manganese Oxides Modified Diatomite. Water Res. 2001, 35, 3724-3728. [CrossRef]

35. Khraisheh, M.A.M.; Al-degs, Y.S.; Mcminn, W.A.M. Remediation of wastewater containing heavy metals using raw and modified diatomite. Chem. Eng. J. 2004, 99, 177-184. [CrossRef]

36. Niu, L.; Xian, G.; Long, Z.; Zhang, G.; Zhou, N. MnCeOx/diatomite catalyst for persulfate activation to degrade organic pollutants. J. Environ. Sci. 2020, 89, 206-217. [CrossRef]

37. He, H.; Luo, Z.; Yu, C. Diatomite-anchored $\mathrm{g}-\mathrm{C}_{3} \mathrm{~N}_{4}$ nanosheets for selective removal of organic dyes. J. Alloys Compd. 2020, 816, 152652. [CrossRef]

38. Gao, R.; Sun, Q.; Fang, Z.; Li, G.T.; Jia, M.; Hou, X. Preparation of nano-TiO 2 /diatomite-based porous ceramics and their photocatalytic kinetics for formaldehyde degradation. Int. J. Miner. Metall. Mater. 2018, 25, 73-79. [CrossRef]

39. Wu, Z.; Zhu, Z.; Hao, X.; Zhou, W.; Han, J.; Tang, X.; Yao, S.; Zhang, X. Enhanced oxidation of naphthalene using plasma activation of $\mathrm{TiO}_{2}$ /diatomite catalyst. J. Hazard. Mater. 2018, 347, 48-57. [CrossRef]

40. Chen, Y.; Liu, K. Preparation of granulated $\mathrm{N}$-doped $\mathrm{TiO}_{2} /$ diatomite composite and its applications of visible light degradation and disinfection. Powder Technol. 2016, 303, 176-191. [CrossRef]

41. Ao, M.; Liu, K.; Tang, X.; Li, Z.; Peng, Q.; Huang, J. BiOCl/TiO $2 /$ diatomite composites with enhanced visible-light photocatalytic activity for the degradation of rhodamine B. Beilstein. J. Nanotech. 2019, 10, 1412-1422. [CrossRef]

42. Xu, H.; Reunchan, P.; Ouyang, S.; Tong, H.; Umezawa, N.; Kako, T.; Ye, J. Anatase $\mathrm{TiO}_{2}$ single crystals exposed with high-reactive $\{111\}$ facets toward efficient $\mathrm{H}_{2}$ evolution. Chem. Mater. 2013, 25, 405-411. [CrossRef]

43. Roy, N.; Park, Y.; Sohn, Y. Green synthesis of anatase $\mathrm{TiO}_{2}$ nanocrystals with diverse shapes and their exposed facets-dependent photoredox activity. ACS Appl. Mater. Interfaces 2014, 6, 16498-16507. [CrossRef]

44. Sun, Z.; Yang, X.; Zhang, G.; Zheng, S.; Frost, R. A novel method for purification of low grade diatomite powders in centrifugal fields. Int. J. Miner. Process. 2013, 125, 18-26. [CrossRef]

45. Liu, E.; Kang, L.; Wu, F.; Sun, T.; Hu, X.; Yang, Y.; Liu, H.; Fan, J. Photocatalytic Reduction of $\mathrm{CO}_{2}$ into Methanol over $\mathrm{Ag} / \mathrm{TiO}_{2}$ Nanocomposites Enhanced by Surface Plasmon Resonance. Plasmonics 2014, 9 , 61-70. [CrossRef]

46. Wu, L.; Zhou, Y.; Nie, W.; Song, L.; Chen, P. Synthesis of highly monodispersed teardrop-shaped core-shell $\mathrm{SiO}_{2} / \mathrm{TiO}_{2}$ nanoparticles and their photocatalytic activities. Appl. Surf. Sci. 2015, 351, 320-326. [CrossRef]

47. Thommes, M.; Kaneko, K.; Neimark, A.V. Physisorption of gases, with special reference to the evaluation of surface area and pore size distribution (IUPAC Technical Report). Pure Appl. Chem. 2015, 87, 1051-1069. [CrossRef]

48. Yu, X.; Zhao, Z.; Zhang, J. One-step synthesis of ultrathin nanobelts-assembled urchin-like anatase $\mathrm{TiO}_{2}$ nanostructures for highly efficient photocatalysis. CrystEngComm 2017, 19, 129-136. [CrossRef] 
49. Xu, H.Q.; Hu, J.; Wang, D.; Li, Z.; Zhang, Q.; Luo, Y.; Yu, S.H.; Jiang, H.L. Visible-light photoreduction of $\mathrm{CO}_{2}$ in a metal-organic framework: Boosting electron-hole separation via electron trap states. J. Am. Chem. Soc. 2015, 137, 13440-13443. [CrossRef]

50. .Kang, Y.; Yang, Y.; Yin, L.C. Selective breaking of hydrogen bonds of layered carbon nitride for visible light photocatalysis. Adv. Mater. 2016, 28, 6471-6477. [CrossRef]

51. Choi, W.; Ko, J.Y.; Park, H.; Chung, J.S. Investigation on $\mathrm{TiO}_{2}$-coated optical fibers for gas-phase photocatalytic oxidation of acetone. Appl. Catal. B Environ. 2001, 31, 209-220. [CrossRef]

52. Liu, S.; Yu, J.; Jaroniec, M. Tunable photocatalytic selectivity of hollow $\mathrm{TiO}_{2}$ microspheres composed of anatase polyhedra with exposed $\{001\}$ facets. J. Am. Chem. Soc. 2010, 132, 11914-11916. [CrossRef]

(C) 2020 by the authors. Licensee MDPI, Basel, Switzerland. This article is an open access article distributed under the terms and conditions of the Creative Commons Attribution (CC BY) license (http://creativecommons.org/licenses/by/4.0/). 